Review Article

\title{
Management of electrical injuries
}

\section{Ketan Vagholkar*, Arpit Murarka, Sandeeta Shetty, Suvarna Vagholkar}

Department of Surgery, D. Y. Patil University School of Medicine, Navi Mumbai - 400706, Maharashtra, India

Received: 30 July 2017

Accepted: 02 August 2017

\section{*Correspondence:}

Dr. Ketan Vagholkar,

E-mail: kvagholkar@yahoo.com

Copyright: ( ) the author(s), publisher and licensee Medip Academy. This is an open-access article distributed under the terms of the Creative Commons Attribution Non-Commercial License, which permits unrestricted non-commercial use, distribution, and reproduction in any medium, provided the original work is properly cited.

\section{ABSTRACT}

With growing industrialization and mechanization of every household electrical injuries are becoming quite common. Electrical injuries are quite intricate with the damage caused. They cause not only external burns injury but a wide spectrum of visceral injuries which in many cases is difficult to diagnose and manage. Therefore, a sound understanding of the engineering aspects is pivotal in diagnosing and managing these cases. A brief review of the pathophysiology and management of electrical injuries is presented.

Keywords: Electrical injuries, Medical surgical management

\section{INTRODUCTION}

With advances in technology and heavy industrialization electrical injuries are on a rise. Data on management of electrical injuries is scarce and scattered. This is because majority of these cases are not studied or reported. Statistical analysis of electrical injuries is necessary to develop safer technologies in order to avert such dangerous injuries. The article reviews the pathophysiology and management of electrical injuries.

\section{Physics of electrical current}

\section{Electric current exists in 2 forms}

- Alternating current

- Direct current

Alternating current is the commonly used domestic power supplier. Electrical current enters the body at the point of contact and travels along the tissues and structures which offers lowest resistance. It exits through the point of contact with the earth. The contact points usually exhibit visual skin injury. ${ }^{1}$ The severity of tissue damage is influenced by three characteristics of electrical current.

\section{Voltage}

High voltage (1000 Volts or more can be fatal) It ionizes the air particles and may arc across several meters, thereby causing damage beyond the point of physical contact. Low voltage injuries usually involve the hands or oral cavity. ${ }^{1,2}$

\section{Amperage}

It determines the heat generated. It usually causes rhythm disturbances in the heart: Ventricular fibrillation is the common effect produced by high amperage current. More the time of contact, more fatal the effect. ${ }^{1,2}$

\section{Resistance}

Tissues which offers least resistance allow maximum passage of current. ${ }^{3}$ These includes blood vessels, nerves, muscles, skin, tendons, fat and bones. Thrombosis of blood vessels is the commonest effect resulting in ischemia or gangrene of the tissues usually some distance 
away from the one's injured. Dry skin offers highest resistance whereas skin immersed under water offers lowest resistance thus, leading to more damage.

\section{PATHOPHYSIOLOGY OF ELECTRICAL INJURIES}

The point of contact of electrical current leads to a central area of charring. This is surrounded by a zone in which tissues though architecturally identifiable yet are nonviable. This is surrounded by a zone of partial necrosis in which vessels are either necrosed or there is significant intimal or medial damage. Muscles are damaged significantly. Myofibrils are destroyed due to coagulation of proteins. Tetanic contraction of muscles particularly with alternating current can cause serious bony injuries. ${ }^{3,4}$

Heat production can cause severe soft tissue damage, sudden forceful propulsion of the body that produces atypical spinal or limb fractures as well as intraperitoneal or intra-thoracic injuries. Therefore, the injuries caused by electricity on the body are best determined by seven factors. ${ }^{5}$

- Type of the current

- Amount of current

- Pathway of current

- Duration of the flow of current

- Area of contact

- Resistance offered by the body

- Voltage.

\section{METABOLIC EFFECTS OF ELECTRICAL INJURIES}

Unexplained hypokalemia which may persists for few hours to few weeks, can cause toxic effects on the heart. This may be explained on the basis of alteration of cell membrane potential causing damage to the electrolytic exchange mechanism across the cell membrane. ${ }^{5,6}$

Myonecrosis is another harmful effect. This can cause myoglobinuria which can lead to acute renal failure. Severe damage to the RBC membranes can cause hemolysis and release of potassium into circulation leading to severe hyperkalemia.

Rhythm abnormalities of the heart with superimposed hyperkalemia can cause sudden cardiac arrest. High voltage currents or high-tension currents can cause a wide variety of systemic effects which include neurological, cardiovascular, and respiratory as well as bone and eye complications.

Awareness of the mechanism of injury caused by various aspects of electric current is therefore pivotal in diagnosing, estimating the severity of damage and formulating a prompt therapeutic algorithm to reduce both the morbidity and mortality.

\section{LOW TENSION INJURIES (less than 1000 Volts)}

These are commonly encountered in the household setups. Children are commonly affected. ${ }^{5}$

\section{Types}

\section{Flash burns}

These are caused by momentary exposure of the skin usually of the face and hands through flash heat, without actual physical contact of the skin to the electrical appliance. The skin looks black and swollen. Such burns are treated by regular cleaning with chlorhexidine, puncturing the blisters and leaving the burns exposed. In case of hand injuries, elevation to reduce edema followed by mobilization under the guidance of physiotherapist is beneficial.

\section{Electrical bar burns}

These usually affect the hands and causes full thickness damage. Tendons and nerves are severely destroyed. The main injuring agent is the heat rather than the current itself. Scarring caused by such injuries is severe leading to impairment of growth potential especially in children. Nerves affected by such injuries should not be divided as there is always a possibility of axonal growth through the burned section. Similarly, the tendon which retains continuity should also be left in place. Such type of injuries requires early excision followed by skin grafting or flap cover. ${ }^{6}$

\section{Injuries caused by contact with livewire}

In these injuries, the patient becomes locked onto the electrical appliance and needs to be disconnected either by turning of the power supply or using a non-conducting material. Though the contact burn is small but because of tetanic contractions the victim is unable to disconnect himself from the source. It is important to look for the point of exit of the current from the body which is usually found on the soles of the feet. Such wounds require daily dressing either with silver sulfadiazine or bactigras. Daily inspection is necessary. Dead necrotic tissue needs to be excised on a periodic basis. Once healthy granulation tissue develops, skin grafting may be done. Special care needs to be exercised in case of hand burns. Supervised physiotherapy is essential to prevent post-operative morbidity in order to conserve manual dexterity. ${ }^{6}$

\section{HIGH TENSION INJURIES (More than 1000 Volts)}

\section{High tension injuries damage the tissues in three ways}

- Electro-trauma with passage of the electric current

- Electric arc

- Secondary flame burns/Ignition of the clothing. 


\section{Electro trauma with passage of the electric current}

The severity of the tissue destruction is very high. Tissues appearing to be normal also becomes gangrenous with time due to microangiopathy causing deteriorating blood supply. Such patients require both prompt surgical and medical management. Medical treatment takes a precedence over the surgical management.

Immediate cardio-pulmonary resuscitation for ventricular fibrillation or asystole may be lifesaving. ECG monitoring and estimation of cardiac enzymes to detect damaged tissue of the heart muscle is carried out. ${ }^{5,6}$ Dead muscle causes severe myoglobinuria even predisposing to gas gangrene requiring surgical debridement and maintenance of adequate urine output by administering plasma protein fractions and blood along with mannitol. Sodium bicarbonate may also be necessary to correct the acidosis. Progressive loss of distal circulation or sensation may necessitate escharotomies, fasciotomies or debridement of dead necrotic muscles. Burns on the abdomen may cause thrombosis of intestinal vessels leading to intestinal gangrene. Careful monitoring for abdominal signs is essential and urgent laparotomy may be necessary if peritonitis develops. ${ }^{7}$

Periodic hemoglobin estimations is essential to detect hemolysis. Monitoring of potassium levels in such cases is pivotal in preventing deleterious effects on the heart. Identification of bone and joint injuries followed by reduction or splintage is necessary for avoidance of physical disability. ${ }^{8}$

\section{Electric arc burns}

High tension arcs cause injury by intense heat or flash. The current may earth itself through the victim in contact with the ground. It may jump to another adjacent object or return back to the source. Cardiac irregularities namely ventricular fibrillation and respiratory failure may result. ${ }^{6}$

\section{Lightning injuries}

\section{Early effects}

- Acute myocardial infarction or arrhythmias

- Muscle necrosis leading to myoglobinuria

- Comma, seizures and amnesia

- Paralysis and hyperesthesia

- Blast injuries: lung, cellular hemorrhage and intraperitoneal hemorrhage

- Gastric or intestinal ileus

\section{Late effects}

- Hemiplegia

- Cataract

- Neuralgias

- Scar Contractures

\section{TREATMENT}

Medical Therapy: Patients of electrical injuries should be evaluated as any other trauma patients. The ABC Protocol with inline immobilization of the spine as per the ATLS guidelines should be made a routine. High index of suspicion for hidden injuries followed by specific investigations will help in the diagnosis of hidden injuries. Intravenous access, cardiac monitoring, measurement of oxygen saturation and placement of a Foley's catheter constitutes the primary management. ${ }^{8,9}$

Initial fluid resuscitation should aim to a urine output of greater than or equal to $0.5 \mathrm{cc} / \mathrm{kg} /$ hour. However, if one is suspecting myoglobinuria then a urine output of $1 \mathrm{cc} / \mathrm{kg} /$ hour is advisable. In lightening burns, as there are extensive superficial burns, any standard burns resuscitation formula can be used. Electric injuries are difficult to assess with respect to the extent of tissue damage. Hence, it is a safe practice to increase the fluid replacement after any electrical injury. An isotonic balanced saline solution is ideal. Close urine output assessment is necessary. Dark urine or hematuria is suggestive of myoglobinuria. This may require more intravenous fluids and bicarbonate. Mannitol in a dose of $1 \mathrm{~g} / \mathrm{kg}$ of body weight is essential to promote osmotic diuresis. Urine Output in such patients should be up to 2$3 \mathrm{cc} / \mathrm{kg} /$ hour with a $\mathrm{pH}$ greater than 6.5 . Bicarbonate administration treats acidosis accompanied with alkalinizaton of the urine rendering myoglobin more soluble. If further diuresis is necessary acetazolamide may be considered as it has a capability to alkalinize the urine. However, the chances of developing hyperosmotic hyperalbuminemia need to be watched for.

Continuous cardiac monitoring for arrhythmias is the main stay of treatment especially in high tension and high voltage injuries. Therefore, housing such patients in the intensive care unit is of great advantage.

\section{Surgical therapy}

Functional outcome of an electrical burns injury is inversely proportional to the time elapsed before the commencement of reconstructive procedures. ${ }^{8,9}$ Optimal management of the wounds involves initial debridement, decompression (Escharotomy/Fasciotomy) and aggressively planned debridement with skin cover in order to preserve vital structures. Impairment of circulation is a common sequela to electrical burns injury. Hence an escharotomy or fasciotomy done promptly can prevent compartment syndrome and help regain vascularity of underlying tissues. Fasciotomy is in fact superior to escharotomy as it helps in determining the extent of muscular necrosis. Repeat assessments at the time of dressing changes help in determining muscle viability, as well as removal of necrotic tissue thereby reducing the chances of infection. In a severely damaged extremity, amputation may be lifesaving. After initial resuscitation and hemodynamic optimization, stress 
should be laid on wound care. Once viability of tissues is ascertained either skin grafting or flaps should be done to achieve cover of the defects.

\section{CONCLUSION}

Understanding the pathophysiology of electrical injury is pivotal in diagnosis of the damage. Traditional primary resuscitation protocols as for any trauma patients should be implemented in the emergency patient department Hemodynamic and metabolic optimization should best be performed in the ICU. Surgical care of the damaged tissues should be done based on periodic assessment of tissue viability.

\section{ACKNOWLEDGMENTS}

Authors would like to thank Parth K. Vagholkar for his help in typesetting the manuscript.

Funding: No funding sources Conflict of interest: None declared

Ethical approval: Not required

\section{REFERENCES}

1. Lee RC. Injury by electrical forces: Pathophysiology, manifestations and management. Curr Prob Surg. 1997;34:677-764.

2. Hunt JL, Mason AD, Masterson TS. The pathophysiology of acute electric burns. J Trauma. 1976:16:335-40.
3. Koumbourlis AC. Electrical injuries. Crit Care Med. 2002;30:424-30.

4. Rai J, Jeschke MG, Barrow RE, Herndon DN. Electrical injuries: a 30-year review. J Trauma. 1999;46:933-6.

5. Arnoldo BD, Purdue GF, Kowalske K, Helm PA, Burris A, Hunt JL. Electrical injuries: a 20-year review. J Burn Care Rehabil. 2004;25:479-84.

6. Luz DP, Millan LS, Alessi MS, Uguetto WF, Paggiaro A, Gomez DS, et al. Electrical burns: a retrospective analysis across a 5-year period. Burns. 2009;35:1015-9.

7. Arnoldo BD, Klein M, Gibran NS. Practice guidelines for the management of electrical injuries. J Burn Care Res. 2006;27:439-47.

8. Hussmann J, Kucan JO, Russell RC, Bradley T, Zamboni WA. Electrical injuries - morbidity, outcome and treatment rationale. Burns. 1995;21:530-5.

9. Lipový B, Řihová H, Kaloudová Y, Suchánek I, Gregorová N, Hokynková A, et al. The importance of a multidisciplinary approach in the treatment of mutilating electrical injury: a case study. Acta Chir Plast. 2010;52:61-4.

Cite this article as: Vagholkar K, Murarka A, Shetty $\mathrm{S}$, Vagholkar S. Management of electrical injuries. Int Surg J 2017;4:2874-7. 